\title{
Memory Training as a Method for Reducing the Misinformation Effect
}

\author{
Malwina Szpitalak ${ }^{1} \cdot$ Adrianna Woltmann $^{1} \cdot$ Romuald Polczyk $^{1}$ (i) $\cdot$ Magdalena Kękuś $^{1}$
}

Published online: 7 November 2019

(C) The Author(s) 2019

\begin{abstract}
The two experiments presented in this study investigate the impact of memory training on the misinformation effect. This effect is particularly important in the forensic context as exposing a witness to misinformation may adversely affect the content of their testimony. During the training, the participants were acquainted with seven (Experiment 1) or six (Experiment 2) types of memory errors. It was expected that knowledge of the unreliability of human memory would reduce the misinformation effect and therefore improve the quality of testimony. These hypotheses were confirmed in both experiments. The efficacy of both the complete and reduced training courses was not statistically different. Additionally, in Experiment 1 the effectiveness of warning against misinformation was replicated: respondents warned about misinformation were more resistant to it than those not warned. The tainted truth effect was also present: people warned against non-existent misinformation had lower correctness in the memory test than non-warned ones. Finally, immediate recall of the content of the original information had no impact on the misinformation effect.
\end{abstract}

Keywords Misinformation effect $\cdot$ Training $\cdot$ Eyewitness testimony $\cdot$ Memory

\section{Introduction}

In court proceedings, eyewitness testimonies often constitute essential evidence that makes it possible to establish the circumstances of an event. Reconstruction of the facts therefore requires witnesses to provide reliable and dependable information. However, forensic practice shows that witnesses who are acting in the best faith and are convinced of the truth of their testimony make blatant mistakes and misdescribe the events they witnessed (Wells \& Olson, 2003; Wells \& Turtle, 1987). As a result, this may lead to the conviction of innocent persons or the acquittal of guilty ones.

In research into the source of such errors, much attention has been paid to a particular type of susceptibility to suggestion, namely the misinformation effect, which is defined as the inclusion in witnesses' testimonies of information that is inconsistent with the course of the event and that comes from sources other than the event (seminal research: Loftus, Miller,

Electronic supplementary material The online version of this article (https://doi.org/10.1007/s12144-019-00490-9) contains supplementary material, which is available to authorized users.

Romuald Polczyk

romuald.polczyk@uj.edu.pl

1 Institute of Psychology, Jagiellonian University, ul. Ingardena 6, 30-060 Kraków, Poland
\& Burns, 1978). Systematic research related to this subject has been conducted since the mid-1970s (e.g. Bekerian \& Bowers, 1983; Loftus, 2005; Loftus et al., 1978; McCloskey \& Zaragoza, 1985; Pezdek, 1977), although earlier reports can be found (Wiśniacka, 1933).

A typical experiment concerning the misinformation effect test usually proceeds according to the following sequence (Loftus et al., 1978): first, participants are presented with some original material, e. g. a short movie or a series of slides. After a break, participants are exposed to postevent material that includes misinformation; for example, a description of the original material which in the experimental group contains some details that are incongruent with the content of the original material. Then, after a break (or sometimes immediately), participants are tested with a memory test of the original material. A typical result that indicates the misinformation effect is a statistically significantly higher number of responses consistent with the misinformation in the experimental group when compared to the control group.

A common technique for mitigating the effect of misinformation is to warn participants about it (Blank \& Launay, 2014; Chambers \& Zaragoza, 2001; Echterhoff, Hirst, \& Hussy, 2005; Greene, Flynn, \& Loftus, 1982; Oeberst \& Blank, 2012; Szpitalak, 2015; Wright, 1993). Even though this method is easy to apply, a so-called tainted truth effect may arise (Echterhoff, Groll, \& Hirst, 2007; Szpitalak, 2015; Szpitalak \& Polczyk, 2010, 2011, 2013) when not misinformed people are warned against misinformation; this 
consists in a decrease in the quality of the testimony, most probably relating to an 'overcorrection' for non-existent misinformation. In real-life situations the interrogator does not usually know whether a particular witness was exposed to misinformation. If a witness did learn some misinformation, a warning would most likely reduce their susceptibility to it; however, if no misinformation reached the witness, a warning may cause them to be uncertain as to what they read in the press or heard from other witnesses and what they actually saw. In the latter case, even if a witness did see something real, they may restrain from reporting it due to overcorrection. Thus, a warning given to a witness can have both positive and negative consequences.

The present study was planned to verify the efficacy of warning against misinformation. In addition, another method was applied, namely training concerning the functioning of human memory, including memory errors. It was assumed that this should reduce the effect of misinformation without compromising the quality of the final testimony when people who are not misinformed are trained, i.e. without causing the tainted truth effect.

The idea that various kinds of training can improve memory is not new. Many methods of improving memory have been researched, ranging from simple ones such as closing the eyes (Vredeveldt \& Penrod, 2013) to computerized programs which claim to be effective in improving various kinds of memory (e.g. Hyer et al., 2016; Swanger, 2015; Zelinski et al., 2011; but see Apter, 2012), or even online sources of memory improvement (Morrell et al., 2006). In general, the usefulness of various procedures has been demonstrated, e.g. active experiencing training (Banducci et al., 2017), mindfulness training (Mrazek, Franklin, Phillips, Baird, \& Schooler, 2013), retrieval practice (Rogalski, Altmann, \& Rosenbek, 2014) and strategic training using mental images (Carretti, Borella, \& De Beni, 2007). Even physical exercise seems to improve memory (Zuniga, Mueller, Santana, \& Kelemen, 2018).

Some kinds of training seemed to reduce false experimentally manipulated memories. For example, in research by Calvillo, Flores and Gonzales (2018), inducing mindfulness seemed to reduce the tendency to falsely recognize critical lures in the Deese-Roediger-McDermott paradigm (Roediger $\&$ McDermott, 1995), which consists in having participants memorize a list of words that are semantically strongly related to a critical lure that is not presented.

In the specific context of eyewitness testimony, training was also reported to be effective. Paterson et al. (2017) showed that training witnesses to concentrate on stable ("internal") features of the face (like the nose, eyes or mouth) improved the accuracy of identification, although only when external features (like hairstyle) changed between the presentation and the identification. In a sample of children, source-monitoring training helped
7- and 8-year-old children (but not younger ones) to avoid giving false reports after hearing their parents describe non-experienced events (Poole \& Lindsay, 2002). This finding is consistent with general findings confirming that metamemory knowledge is positively linked to memory performance in children (Geurten, Catale, \& Meulemans, 2015). Also, in a sample of adults, Lane, Roussel, Villa and Morita (2007) were able to show that teaching participants to recognize differences in the phenomenal experience that accompanies veridical and false memories and providing feedback concerning the correctness of answers helps them to make source-monitoring decisions.

We were only able to locate two studies concerning the possibility that providing information about memory functioning may help resist misinformation in the classical threestage paradigm (not in the source-monitoring context). One of them investigated the influence of inoculation on susceptibility to misinformation in a standard three-stage procedure (Winkelspecht \& Mowrer, 1999) in which the authors used a technique that combined warning and "vaccination" against misinformation. The research consisted of presenting the original material to the examined people in the form of a fragment of a film about dangerous road traffic situations. In the next stage, some of the participants were subjected to the inoculation procedure, and then some of the respondents were misinformed. At the end of the procedure, all participants completed a memory test on the original material. The inoculation was a five-minute lecture on the unreliability of human memory and was given in the form of text and/or video. The lecture taught that accuracy in the final "testimony" was more important than the satisfaction of the experimenter. It also stressed the consequences of providing false information, such as the conviction of an innocent person. Moreover, the lecture warned that the participants might have received false information during the procedure. In the experiment described above, inoculation - contrary to the authors' expectations increased the susceptibility to misinformation, but it did not affect the result of the memory test of participants who had not been misinformed.

Another study of this kind was presented by Saywitz and Moan-Hardie (1994) with the participation of seven-year-olds. The whole test procedure was spread over two days. On the first day, the children underwent training focused on issues similar to those raised in the lecture presented during the inoculation in the study by Winkelspecht and Mowrer (1999). Furthermore, during the training the children practiced resisting suggestions. The training started with the presentation of a sound recording in which a child succumbing to suggestions was the main character. Afterwards, the reasons that the child in the recording yielded to suggestions were discussed with the participants and the consequences of incorrect answers were pointed out. The children were taught that the satisfaction of the experimenter or any other adult is less 
important than telling the truth. The benefits of truthfulness were also emphasized. In the next step the children were taught a question-answering strategy which put emphasis on answering only after reflecting on the question and comparing the information expected by the questioner with their own memory. At this stage, children also learned to answer "I don't know" when they had forgotten something they were asked about. In addition, they were shown how to resist the suggestions included in the questions. After teaching the children the strategy of responding to questions, a film was presented to them, after which they practiced the learnt strategies. On the next day, the children were reminded of the recommendations from the previous day and the main experimental procedure was carried out. The results confirmed that children subjected to training (compared to those who were not) were more resistant to misinformation.

One problem with the studies by Winkelspecht and Mowrer (1999) and Saywitz and Moan-Hardie (1999) is the fact that the training was applied before the children were exposed to misinformation. As opposed to a retrospective warning, this represents a kind of "prospective warning" (Echterhoff et al., 2005; Schul, Liu, Xu, Flamand, \& Vasudevan, 2007) that is given before the misinformation is given. This reduces the ecological validity of the results as in real-life situations any means of reducing the effects of misinformation are usually only possible after a witness has been exposed to various sources of misinformation.

Compared to the research presented above, the present study relates to experiments in which some kind of metamemory was the content of the training. It consists of a three-stage misinformation procedure which refers directly to the content of the memory report, not to the ability to discriminate between sources of information, as in the study by Lane et al. (2007). This is important because a person may be able to recognize sources of information and be aware of the discrepancies between the original and postevent misinformation and still give answers consistent with the latter (Blank, 1998; Polczyk, 2007, 2017). Also, in the present research the training consisted solely of providing participants with information about memory, or - more precisely - about possible weaknesses and malfunctions of memory. Hultsch, Hertzog, Dixon and Davidson (1988) identified four broad aspects of metamemory: (1) knowledge about memory processes, (2) memory monitoring, (3) sense of memory efficacy, and (4) memory-related affect. The training applied in the present study refers directly to the first aspect listed above, although it is possible that it also affected the remaining three. Unlike the studies of Winkelspecht and Mowrer (1999) and Saywitz and Moan-Hardie (1999), the intervention occurred after the misinformation was exposed. Also, in contrast to the study of Saywitz and Moan-Hardie (1999), no practicing of giving correct answers of any sort was applied; in the present study, the training consisted solely in providing information.
In the present study it was assumed that the better the metacognitive abilities of an individual and their knowledge about the deficits of memory, the less their susceptibility to misinformation (Roebers, 2002). Making an individual aware that memory is unreliable and that it is easy to succumb to illusions related to its functioning should activate their metacognitive ability to monitor the source of information (see Koriat \& Goldsmith, 1996).

Apart from increasing their metacognitive abilities, making someone aware of weaknesses of memory may increase their attention. After training, participants may start to inspect the content of their memories more closely; this may increase the chance of detecting discrepancies between the original and postevent materials. Although detecting discrepancies by no means prevents the misinformation effect from happening (Blank, 1998; Polczyk, 2007, 2017), it nevertheless reduces it (Tousignant, Hall, \& Loftus, 1986). It is even possible that some motivational processes take place as some people may feel challenged in a way when they learn that memory is generally weak, therefore they may want to show that their own memory is good.

The purpose of the training used in the research presented in this article was to make participants familiar with the seven types of memory errors that were classified and described by Schacter (1999): (1) the sin of impermanence - forgetting past events over time under the influence of new experiences; (2) the sin of distraction - forgetting everyday matters due to their erroneous coding or omission in an attempt to extract; (3) the sin of blocking - blocking information known to the subject as a result of other information that occupies attention and blocks the discovery of information needed at a given moment; (4) the sin of erroneous attribution - combining individual elements of an experience into one whole due to the erroneous linking of an event to a time or place; (5) the sin of susceptibility to suggestion - a key error in the presented study which consists in including misleading information from other sources, e.g. from another person or from an individual's own memories (this is caused by the tendency of memory to change information under the influence of a large amount of information or suggestive questions); (6) the sin of bias distorting the memory of past events so that they are consistent with the current views and needs of the subject (the reason for these distortions is the filtering of past events by present knowledge); (7) the sin of persistence - the continuous return of a given recollection due to the high clarity of a given memory trace.

In addition, in the present study a procedure was used in which participants reported the content of the original material before the postevent information was administered (initial testing). This procedure is more "ecologically valid" than the classic one as in reality witnesses often give their testimony shortly after a given event, before 
any misinformation can possibly reach them (Chan, Thomas, \& Bulevich, 2009; Thomas, Bulevich, \& Chan, 2010). Immediate testing was expected to improve the recollection of the original material as a result of directly testing the memory of this material (Tulving, 1967). Interestingly, immediate recollection may also result in an increase in susceptibility to misinformation; this effect is called retrieval-enhanced suggestibility (Thomas et al., 2010), but this result was not systematically replicated (e.g. Chan \& LaPaglia, 2011; Huff et al., 2013; Pansky \& Tenenboim, 2011). Also, Szpitalak (2015) demonstrated the opposite effect, i.e. a decrease in the size of the misinformation effect in people who had undergone the initial testing procedure compared to those had not.

To summarize, training can be a method of reducing the misinformation effect that - unlike warning against misinformation - should not have negative effects if the witness has not been misinformed. In the present study, its effectiveness was compared to warning against misinformation and was studied in the context of initial testing.

\section{Experiment 1}

The aim of Experiment 1 was to investigate the effect of recalling the original material (initial testing), warning against misinformation, and training about the unreliability of human memory on the misinformation effect. On the basis of the reasoning presented in the Introduction, the following hypotheses were formulated:

1. The misinformation effect will be replicated (the correctness of the answers in the memory test will be lower in the case of misinformed people than for those who were not misinformed).

2. Recalling the original material shortly after its exposure will reduce the misinformation effect (correctness in the memory test will be higher in the case of people who recalled the original material content just after its exposure than for those who did not do so).

3. Training on the unreliability of memory will reduce the misinformation effect (correctness in the memory test will be higher in people undergoing training than in those who did not).

4. The warning will reduce the effect of misinformation (people warned of misinformation before the memory test will have a higher level of correctness than those not warned).

5. The tainted truth effect will be present (people warned against non-existent misinformation will have lower correctness in the memory test than non-misinformed and not warned people).

\section{Method}

Participants The research involved 556 people (359 women and 197 men), all of whom were students of high schools and universities in Kraków, Poland. Their mean age was 17.64 $(S D=2.07$; range 15-31). The procedure was identical for the two types of students. Participation in the study was voluntary and informed oral consent was obtained. The participants did not receive any financial gratification.

Materials A three-minute film recording was used as the original material. In the film, a boy steals a camera from a man, which prompts a chase between the two. It ends with the boy running out into the street and getting hit by a car.

The immediate testing consisted in written free recollection of the original material; in the control condition without initial testing, a filler task was applied. The postevent material consisted of a description of the film that contained seven misleading details in the group of misinformed people, or repetition of elements consistent with the content of the film for the control group. The training about memory functioning explained the memory errors listed by Schacter (1999): transience, absent-mindedness, blocking, misattribution, suggestibility, bias, and persistence. In the control group the training concerned soft skills related to social attitudes. The final memory test contained 20 two-alternative forced-choice questions. Seven of them were critical: the participants had to choose between an answer consistent with the original or with the postevent information. In the warning condition, the memory test was preceded by a warning about possible discrepancies between the original and postevent materials. In the control condition no warning was given. The study also used some other materials to fill the time between manipulations.

Procedure The research was carried out during classes in high schools and universities. The experimenter introduced herself as a student of Jagiellonian University who was conducting scientific research related to the amendment of the Penal Code and the Code of Criminal Procedure. Participants were informed that the research was anonymous and participation in it was voluntary. Afterwards, the film (original material; OM) was presented to participants. In one group the participants performed free recollection of the film's content, and in the reference group a memory-activating procedure that was unrelated to the OM was applied. Approximately $17 \mathrm{~min}$ after the presentation of the original material, the participants were given the postevent material to read; this contained misleading information in the misinformed group and repetition of the information present in the film in the control group. Immediately after reading the postevent material, the participants took part in the training on memory errors (or on soft skills in the reference group). The final memory test for the OM was then applied; in the warned group this was preceded 
by a written warning (emphasized with bold and underlined text) against mistakes in the postevent material. No warning was presented in the reference group. In sum, the research design included four between-subjects factors, each one with two levels: initial testing (present vs. absent $) \times($ misinformation (present vs. absent) $\times$ memory training (present vs. absent $) \times$ warning (present vs. absent). The data were analyzed by means of a $2 \times 2 \times 2 \times 2$ ANOVA. All hypotheses were formulated a priori, therefore - according to existing recommendations - a series of planned comparisons was applied as the main method (Keppel \& Wickens, 2004; Rosenthal \& Rosnow, 1985). The sample size $(N=556)$ ensured about 30 participants in each cell, thus ensuring reasonable power for the planned comparisons.

\section{Results and Discussion}

Firstly, it was determined whether the two groups of students (high school and university) differed in the memory test. They did not $\left(F(1,552)=80.47, p=.154, \eta^{2}<.01\right)$; the interaction of the group with the misinformation factor was also not significant $\left(F(1,552)<.01, p=.986, \eta^{2}\right.$ $<.01)$.

The mean number of correct answers across experimental conditions is presented in Table 1 . The first hypothesis, which concerns higher correctness in the case of non-misinformed participants in comparison to misinformed ones, was confirmed $(F(1,540)=94.38$, $\left.p<.001, \eta^{2}=.15\right)$. The average correctness of answers in the group of non-misinformed participants was 4.97 $(S D=1.00)$; in the misinformed group it was $3.90(S D=$ 1.49). This is yet another replication of the misinformation effect.

According to the second hypothesis, it was expected that the testing effect would be replicated, i.e. higher correctness in the memory test in misinformed people subjected to the direct testing procedure compared to misinformed people not subjected to this procedure. This expectation was not confirmed $\left(F(1,540)=1.51, p=.220, \eta^{2}<.01\right)$, therefore the second hypothesis was not confirmed.

The hypothesis that training would reduce the misinformation effect was confirmed $(F(1,540)=9.77 p=.002$, $\eta^{2}=.02$ ). The average correctness of answers in the group of untrained, misinformed people was $3.20(S D=1.73)$, while in the group of misinformed people who had undergone training it was $4.09(S D=1.55)$. Moreover, it was not found that the training reduced the correctness in the group of nonmisinformed participants $\left(F(1,540)=0.578, p=.448 ; \eta^{2}\right.$ $<.01$ ). In the non-trained group (without free recollection, without training and without warning) the average accuracy of answers was $5.40(S D=0.85)$ and in the trained group (also without free recollection and without warning) it was 5.00 $(S D=0.98)$.
Table 1 Mean numbers of correct answers (standard deviations) across experimental conditions in Experiment 1

\begin{tabular}{|c|c|c|c|c|c|}
\hline Training & Warning & Initial testing & Not misled & Misled & Total \\
\hline \multirow[t]{9}{*}{ Absent } & \multirow[t]{3}{*}{ Absent } & Absent & $5.24(0.85)$ & $3.20(1.73)$ & 4.09 (1.74) \\
\hline & & Present & $5.41(0.67)$ & $3.58(1.45)$ & $4.59(1.41)$ \\
\hline & & Total & $5.31(0.77)$ & 3.33 (1.64) & $4.29(1.63)$ \\
\hline & \multirow[t]{3}{*}{ Present } & Absent & $4.60(1.10)$ & $4.19(1.21)$ & $4.35(1.18)$ \\
\hline & & Present & $4.79(1.13)$ & $3.87(1.78)$ & $4.31(1.56)$ \\
\hline & & Total & $4.69(1.11)$ & $4.06(1.45)$ & $4.33(1.35)$ \\
\hline & \multirow[t]{3}{*}{ Total } & Absent & $4.96(1.01)$ & 3.69 (1.57) & $4.21(1.50)$ \\
\hline & & Present & $5.12(0.96)$ & $3.73(1.62)$ & 4.45 (1.49) \\
\hline & & Total & $5.03(0.99)$ & $3.70(1.59)$ & $4.31(1.50)$ \\
\hline \multirow[t]{9}{*}{ Present } & \multirow[t]{3}{*}{ Absent } & Absent & $5.00(0.98)$ & $4.09(1.55)$ & $4.52(1.38)$ \\
\hline & & Present & $5.24(0.99)$ & $4.31(1.28)$ & $4.72(1.24)$ \\
\hline & & Total & $5.12(0.98)$ & $4.21(1.41)$ & $4.62(1.31)$ \\
\hline & \multirow[t]{3}{*}{ Present } & Absent & $4.85(0.95)$ & $4.12(1.07)$ & $4.51(1.06)$ \\
\hline & & Present & $4.60(1.05)$ & $3.97(1.53)$ & $4.32(1.31)$ \\
\hline & & Total & $4.72(1.00)$ & $4.04(1.31)$ & $4.42(1.20)$ \\
\hline & \multirow[t]{3}{*}{ Total } & Absent & $4.91(0.96)$ & $4.11(1.31)$ & $4.51(1.21)$ \\
\hline & & Present & $4.86(1.07)$ & $4.14(1.41)$ & $4.51(1.29)$ \\
\hline & & Total & $4.89(1.01)$ & $4.13(1.36)$ & $4.51(1.25)$ \\
\hline \multirow[t]{9}{*}{ Total } & \multirow[t]{3}{*}{ Absent } & Absent & $5.14(0.91)$ & $3.56(1.71)$ & $4.27(1.61)$ \\
\hline & & Present & $5.33(0.83)$ & 4.00 (1.39) & $4.66(1.32)$ \\
\hline & & Total & $5.23(0.87)$ & 3.75 (1.59) & $4.44(1.50)$ \\
\hline & \multirow[t]{3}{*}{ Present } & Absent & $4.74(1.02)$ & $4.16(1.15)$ & $4.43(1.12)$ \\
\hline & & Present & $4.68(1.08)$ & $3.92(1.64)$ & $4.32(1.42)$ \\
\hline & & Total & $4.71(1.05)$ & $4.06(1.38)$ & $4.38(1.27)$ \\
\hline & \multirow[t]{3}{*}{ Total } & Absent & $4.93(0.98)$ & $3.86(1.48)$ & $4.35(1.38)$ \\
\hline & & Present & $4.98(1.02)$ & $3.96(1.51)$ & $4.48(1.38)$ \\
\hline & & Total & $4.97(1.00)$ & $3.90(1.49)$ & $4.41(1.38)$ \\
\hline
\end{tabular}

It seems then that knowledge about the deficits in the functioning of one's own memory effectively reduced the effects of misinformation. This confirms the assumption that awareness about the unreliability of memory can lead to activation of the metacognitive ability to better monitor the source of information and to better control responses. This can also reduce the decision-making criteria when a person is uncertain whether what they remember is from the original source. It is worth stressing here once again the high ecological accuracy of this method: regardless of the misinformation received by a witness after an event, training them before the interrogation should improve the quality of the report. Importantly, the training of a witness who has not been exposed to misinformation does not seem to impair the quality of their report, as may be the case with a warning.

The fourth hypothesis concerned the influence of the warning on the correctness of memory test execution in the misinformed group; this was confirmed $(F(1,540)=14.91$, $p<.001, \eta^{2}=.03$ ). The average correctness in the group of misinformed, warned participants was $4.19(S D=1.21)$, while 
in the group of misinformed unwarned participants it was 3.20 $(S D=1.73)$.

The tainted truth effect was also observed, according to the fifth hypothesis $F(1,540)=4.33, p=.039$; $\left.\eta^{2}=.01\right)$. The average correctness of answers in the memory test of non-misinformed warned participants was $4.60(S D=1.10)$, while in the group of unwarned, non-misinformed participants it was $5.24(S D=0.85)$.

The most important of the results above is related to the third hypothesis, i.e. confirmation of the effectiveness of training on the unreliability of human memory in reducing the misinformation effect. It should be noted, however, that one of the memory mistakes reported to the participants was the sin of susceptibility to suggestion (Schacter, 1999). Therefore, it cannot be ruled out that the effectiveness of the training in reducing the misinformation effect in this experiment may be due to the warning against suggestions. In other words, it is possible that warning respondents about the susceptibility to suggestion error actually warns them about the misinformation effect. Experiment 2 addressed this problem by eliminating this information from the training on memory.

\section{Experiment 2}

The aim of the second study was to compare the two different types of training in terms of their impact on the size of the misinformation effect. It was investigated whether training which did not include information about the sin of susceptibility to suggestion would be as effective as the full training used in Experiment 1. If the efficacy of training was not limited to a simple warning against misinformation, the reduced training presented in this study should also reduce the misinformation effect. No warning and initial testing was applied in Experiment 2.

In the second experiment the following hypotheses were verified:

1. The misinformation effect will be replicated (correctness in the final test will be significantly lower in misinformed than in non-misinformed participants).

2. Training on the unreliability of memory will reduce the misinformation effect (correctness in the final test will be higher in people undergoing training than in people not undergoing training).

3. Training on the unreliability of memory that does not contain information about the suggestibility error will reduce the misinformation effect (correctness in the final test will be higher in people undergoing training than in people not undergoing training).

\section{Method}

Participants The study involved 194 people (134 women and 60 men), all of whom were students of high schools and universities in Kraków, Poland. Their mean age was 18.30 (SD= 2.55; range 15-29). The procedure was identical for the two types of students. Participation in the study was voluntary and informed oral consent was obtained. The participants did not receive any financial or other gratification.

Materials and Procedure The materials and procedure were the same as in Experiment 1, except that no warning was applied, the second version of the training that did not contain the information about memory suggestibility was added, and no initial testing took place. The research design included two between-subjects factors: misinformation (present vs. absent) $\times$ memory training (full vs. reduced vs. no training) The data were analyzed by means of a $2 \times 3$ ANOVA, including planned comparisons. The sample size $(N=194)$ ensured about 30 participants in each cell.

\section{Results and Discussion}

The two groups of students (high schools and universities) did not differ on the mean number of correct answers, neither in the analysis with the group as the main factor $(F(1,190)=$ $\left.0.23, p=.632, \eta^{2}<.01\right)$, nor in interaction with misinformation $\left(F(1,190)=0.01, p=.907, \eta^{2}<.01\right)$.

The mean number of correct answers across experimental conditions is presented in Table 2 . The hypothesis concerning the misinformation effect was confirmed $(F(1,188)=41.01$, $\left.p<.001, \eta^{2}=.18\right)$. The average correctness of answers in the memory test in the non-misinformed group was $5.37(S D=$ $0.70)$, while in the misinformed group it was $4.36(S D=1.42)$. Thus, the misinformation effect was replicated again.

As expected in the second hypothesis, the full training reduced the size of the misinformation effect $(F(1,188)=4.56$, $\left.p=.034 ; \eta^{2}=.02\right)$. The average accuracy of answers in the case of misinformed people who had undergone training was $4.56(S D=1.26)$, while in the case of misinformed people who had not undergone training it was $3.97(S D=1.73)$. This result corresponds with the result obtained in study 1 .

Table 2 Mean numbers of correct answers (standard deviations) across experimental conditions in Experiment 2

\begin{tabular}{llll}
\hline Training & Not misled & Misled & Total \\
\hline Full & $5.23(0.67)$ & $4.56(1.26)$ & $4.88(1.07)$ \\
Reduced & $5.56(0.66)$ & $4.52(1.20)$ & $5.04(1.09)$ \\
None & $5.31(0.74)$ & $3.97(1.73)$ & $4.66(1.47)$ \\
Total & $5.37(0.70)$ & $4.36(1.42)$ & $4.87(1.22)$ \\
\hline
\end{tabular}


Therefore, this is further confirmation of the effectiveness of the training in terms of reducing the misinformation effect.

In the case of the third hypothesis, it was also expected that the reduced form of training would be effective in reducing the misinformation effect. This hypothesis was also confirmed, although the $p$ value was barely significant $(F(1,188)=$ $3.86, p=.050 ; \eta^{2}=.02$ ). The average number of correct answers in misinformed participants who had undergone training was $4.52(S D=1.20)$, while in misinformed people who had not undergone training it was $3.97(S D=1.73)$.

Additionally, both types of training (complete and reduced) were compared. There were no statistically significant differences between them $\left(F(1,188)=0.03, p=.871, \eta^{2}<.01\right)$. Importantly, in this study it was also found that none of the training sessions reduced the correctness of the answers in the group of non-misinformed people. A comparison was made between the training with no mention of the suggestibility error and the untrained group, and the difference was not significant: $F(1,188)=.10, p=.756, \eta^{2}<.01$. The average correctness of responses for the reduced training was 5.56 $(S D=0.66)$ and for the reference group it was $5.31(S D=$ $0.66)$. The correctness of answers given by participants who received the complete training also did not differ significantly from the untrained group $\left(F(1,188)=0.82, p=.367, \eta^{2}\right.$ $<.01)$. The average correctness of answers for the complete training was $5.23(S D=0.67)$.

It seems, therefore, that the efficacy of training is not limited solely to a warning against misinformation: even if no such warning was present, the memory training was still effective. Moreover, its efficacy did not differ significantly from the training in which warning was included. Generally, according to these results knowledge about the basic malleability of human memory may attenuate the effects of false information on the quality of witness testimony.

\section{General Discussion}

The present research concerned the memory misinformation effect, which consists in participants including information in their recollections which was not present in the original material but stemmed from some other sources. The main aim of the present study was to analyze two methods that could undo the effects of misinformation: warning against misinformation and training about "memory sins". The efficacy of both these methods was also explored in the context of initial memory testing - a procedure in which participants recall the content of the original material before they are exposed to misinformation.

Two experiments were performed which differed as regards the version of the training applied. First of all, in both experiments the misinformation effect was replicated: misled participants included more details suggested to them by the postevent material than did the non-misled ones. This is important for the main aim of the present study (if there was no misinformation effect, the methods of reducing it would be meaningless). However, this is also yet another warning about the universality and replicability of this effect, which is worrisome because erroneous reports by witnesses may result in severe judicial mistakes.

In the first experiment, initial testing was manipulated: half of the participants recalled the content of the initial video, the other half did not. This was done for an important reason: in real-life situations witnesses often give an initial memory report just after a given event, e.g. to the police who arrive on the scene. The results concerning this manipulation proved nonsignificant.

As mentioned in the Introduction, the existing results concerning initial testing are not unambiguous: in some experiments immediate recollection improved the results of the participants, but in other ones retrieval-enhanced suggestibility was present: initial testing seemed to increase the misinformation effect. LaPaglia and Chan (2013) listed a few methodological differences between studies in which the testing effect occurred and studies in which the retrieval-enhanced suggestibility effect was found. LaPaglia and Chan indicate, for example, discrepancies in the original material, the centrality of critical details, or the form of the final test. Perhaps these elements or a combination thereof had an influence on the present results. Certainly, the initial recall procedure requires further exploration and the unambiguous factors that influence the suggestibility effect need to be determined.

In the present study, the most often researched method of reducing the effects of suggestible influence, namely warning participants against possible misinformation included in the postevent material, was effective: the answers of warned participants were less contaminated with misinformation than those of participants who were not warned. It should be stressed that this result is not always present. While warning is effective to some degree in most research (e.g. Blank, 1998; Greene et al., 1982; Szpitalak, 2015; Wright; 1993), its effects range from no effect at all to a complete elimination of errors caused by misinformation (for a review and meta-analysis, see Blank \& Launay, 2014). Also, a warning can have adverse effects on the quality of testimony in the case of warned but not misled participants, as was also noted in the present research. Thus, warning may not be the most effective method of reducing the misinformation effect.

In light of this, the results concerning training that informs participants about some of the imperfections of human memory seem promising. It was effective in both experiments: in the first one, in which the list of memory sins included the susceptibility of memory to suggestions, and also in the second one, in which the information that memory is susceptible to suggestion and misinformation was omitted. Moreover, the effects of both versions of training (with and without the 
information about the impact of suggestion) were not different. This confirms the main hypotheses of the present study and is good news for applied forensic psychology: the possible negative effects of wrong information reaching a witness before they give testimony can be undone, at least to some degree.

In the Introduction a few possibilities were listed that implied that the training about memory should be effective: increased metacognitive abilities, increased attention to detection of discrepancies and increased motivation to show that one's memory is good. On the basis of the present data it is not possible to determine which of these interpretations (or more than one of them) had the desired effect. In particular, it is unclear whether the training had the effect of increasing participants' involvement in information processing, or whether it increased their efforts. Further research is needed, including suitable manipulation checks. For example, the hypothesis concerning motivational factors could be analyzed via a mediation analysis in which the training is the predictor, the motivation to show a good memory is the mediator and yielding to misinformation is the outcome. If it is true that training about memory promotes discrepancy detection, this could be detected by existing methods of detecting participants aware of these discrepancies (Blank, 1998; Polczyk, 2017).

It is worth stressing that the training did not generate the tainted truth effect: it did not reduce the quality of answers of participants who were not given misinformation about the original material. This is understandable because the training and warning most probably operate via different mechanisms. The warning simply alerts the witness to possible discrepancies between the original and postevent materials. When there are no discrepancies, overcorrection takes place (Echterhoff et al., 2007): the witness tries to find inconsistencies and "finds" them even if they are not real. In contrast, the efficacy of the training is most probably based on metacognitive abilities and/or increased attention. In the light of the lack of the tainted truth effect, it is somewhat less probable that its efficacy is based on increased motivation because such increased motivation should also lead to overcorrection and therefore to the tainted truth effect.

\section{Limitations and Future Directions}

The effect sizes associated with the training were not very high; $\eta^{2}$ equaled .02 , which means that the training explained about $2 \%$ of the decrease in correcntess due to misinformation. However, this result is at least promising, and more research is needed as regards the efficacy of this method in various settings.

In the control group, the not misinformed participants were presented with information consistent with the film. This is not the best procedure for studying the misinformation effect as it is unclear whether the control participants responded correctly more often than the misinformed participants due to the lack of misinformation or because they were given the correct answers during the postevent stage. However, this procedure was needed to analyze the possible tainted truth effect, which consists in a decrease in the number of correct answers in the group that was not misled but was warned. In the second experiment, in which no warning was applied, this procedure was the same in order to make the results of both experiments comparable. The present results need to be confirmed in experiments using different kinds of the final memory test.

\section{Conclusions}

The misinformation effect is a phenomenon that is systematically demonstrated in empirical research. In this article it was once again shown that this phenomenon may adversely affect the quality of witnesses' testimonies. In relation to the important role that witnesses' testimonies play in the administration of justice (Wells, Memon, \& Penrod, 2006), it is extremely important to know and counteract their limitations.

Training seems to be a promising way of reducing susceptibility to the effect of misinformation and may help increase the quality of witnesses' testimonies. Importantly, training is an easily learned method that can easily be used in practice by lawyers and policemen.

\section{Compliance with Ethical Standards}

All ethical standards were followed in this study.

Conflict of Interest The authors declare that they have no conflict of interest.

Informed Consent Informed consent was obtained from all participants.

Open Access This article is distributed under the terms of the Creative Commons Attribution 4.0 International License (http:// creativecommons.org/licenses/by/4.0/), which permits unrestricted use, distribution, and reproduction in any medium, provided you give appropriate credit to the original author(s) and the source, provide a link to the Creative Commons license, and indicate if changes were made.

\section{References}

Apter, B. J. B. (2012). Do computerised training programmes designed to improve working memory work? Educational Psychology in Practice, 28(3), 257-272.

Banducci, S. E., Daugherty, A. M., Biggan, J. R., Cooke, G. E., Voss, M., Noice, T., \& Kramer, A. F. (2017). Active experiencing training improves episodic memory recall in older adults. Frontiers in Aging Neuroscience, 9.

Bekerian, D. A., \& Bowers, J. M. (1983). Eyewitness testimony: Were we misled? Journal of Experimental Psychology: Learning, Memory, and Cognition, 9(1), 139-145. 
Blank, H. (1998). Memory states and memory tasks: An integrative framework for eyewitness memory and suggestibility. Memory, 6 , $481-529$.

Blank, H., \& Launay, C. (2014). How to protect eyewitness memory against the misinformation effect: A meta-analysis of post-warning studies. Journal of Applied Research in Memory and Cognition, 3(2), 77-88.

Calvillo, D. P., Flores, A. N., \& Gonzales, L. C. (2018). A brief mindfulness induction after encoding decreases false recognition in the Deese-Roediger-McDermott paradigm. Psychology of Consciousness: Theory, Research, and Practice, 5(2), 131-139.

Carretti, B., Borella, E., \& De Beni, R. (2007). Does strategic memory training improve the working memory performance of younger and older adults? Experimental Psychology, 54(4), 311-320.

Chambers, K. L., \& Zaragoza, M. S. (2001). Intended and unintended effects of explicit warnings on eyewitness suggestibility: Evidence from source identification tests. Memory \& Cognition, 29(8), $1120-1129$.

Chan, J. C., \& LaPaglia, J. A. (2011). The dark side of testing memory: Repeated retrieval can enhance eyewitness suggestibility. Journal of Experimental Psychology: Applied, 17(4), 418-432.

Chan, J. C., Thomas, A. K., \& Bulevich, J. B. (2009). Recalling a witnessed event increases eyewitness suggestibility: The reversed testing effect. Psychological Science, 20(1), 66-73.

Echterhoff, G., Groll, S., \& Hirst, W. (2007). Tainted truth: Overcorrection for misinformation influence on eyewitness memory. Social Cognition, 25(3), 367-409.

Echterhoff, G., Hirst, W., \& Hussy, W. (2005). How eyewitnesses resist misinformation: Social postwarnings and the monitoring of memory characteristics. Memory \& Cognition, 33(5), 770-782.

Geurten, M., Catale, C., \& Meulemans, T. (2015). When children's knowledge of memory improves children's performance in memory. Applied Cognitive Psychology, 29(2), 244-252.

Greene, E., Flynn, M. S., \& Loftus, E. F. (1982). Inducing resistance to misleading information. Journal of Memory and Language, 21(2), 207-219.

Hyer, L., Scott, C., Atkinson, M. M., Mullen, C. M., Lee, A., Johnson, A., \& Mckenzie, L. C. (2016). Cognitive training program to improve working memory in older adults with MCI. Clinical Gerontologist: The Journal of Aging and Mental Health, 39(5), 410-427.

Huff, M. J., Davis, S. D., \& Meade, M. L. (2013). The effects of initial testing on false recall and false recognition in the social contagion of memory paradigm. Memory \& Cognition, 41(6), 820-831.

Hultsch, D. F., Hertzog, C., Dixon, R. A., \& Davidson, H. (1988). Memory self-knowledge and self-efficacy in the aged. In M. L. Howe \& C. J. Brainerd (Eds.), Cognitive development in adulthood: Progress in cognitive development research (pp. 65-92). New York: Springer-Verlag.

Keppel, G., \& Wickens, T. D. (2004). Design and analysis (4th ed.). Englewood Cliffs: Prentice-Hall.

Koriat, A., \& Goldsmith, M. (1996). Monitoring and control processes in the strategic regulation of memory accuracy. Psychological Review, 103(3), 490-517.

Lane, S. M., Roussel, C. C., Villa, D., \& Morita, S. K. (2007). Features and feedback: Enhancing metamnemonic knowledge at retrieval reduces source-monitoring errors. Journal of Experimental Psychology: Learning, Memory, and Cognition, 33(6), 1131.

LaPaglia, J. A., \& Chan, J. C. (2013). Testing increases suggestibility for narrative-based misinformation but reduces suggestibility for question-based misinformation. Behavioral Sciences \& the Law, 31(5), 593-606.

Loftus, E. F. (2005). Planting misinformation in the human mind: A $30-$ year investigation of the malleability of memory. Learning \& Memory, 12(4), 361-366.
Loftus, E. F., Miller, D. G., \& Burns, H. J. (1978). Semantic integration of verbal information into a visual memory. Journal of Experimental Psychology: Human Learning and Memory, 4(1), 19-31.

McCloskey, M., \& Zaragoza, M. (1985). Misleading postevent information and memory for events: Arguments and evidence against memory impairment hypotheses. Journal of Experimental Psychology: General, 114(1), 1-16.

Morrell, R. W., Rager, R., Harley, J. P., Herrmann, D. J., Rebok, G. W., \& Parente, R. (2006). Developing an online intervention for memory improvement: The sharper memory project. Cognitive Technology, 11(2), 34-46.

Mrazek, M. D., Franklin, M. S., Phillips, D. T., Baird, B., \& Schooler, J. W. (2013). Mindfulness training improves working memory capacity and GRE performance while reducing mind wandering. Psychological Science, 24(5), 776-781.

Oeberst, A., \& Blank, H. (2012). Undoing suggestive influence on memory: The reversibility of the eyewitness misinformation effect. Cognition, 125(2), 141-159.

Pansky, A., \& Tenenboim, E. (2011). Inoculating against eyewitness suggestibility via interpolated verbatim vs. gist testing. Memory \& Cognition, 39(1), 155-170.

Paterson, H. M., Luppino, D., Calderwood, C., MacDougall, H. G., Taubert, J., \& Kemp, R. I. (2017). Can training improve eyewitness identification? The effect of internal feature focus on memory for faces. Psychology, Crime \& Law, 23(10), 927-945.

Pezdek, K. (1977). Cross-modality semantic integration of sentence and picture memory. Journal of Experimental Psychology: Human Learning and Memory, 3(5), 515-524.

Polczyk, R. (2007). Mechanizmy efektu dezinformacji w kontekście zeznań świadka naocznego. [Mechanisms of the memory misinformation effect in the context of eyewitness testimony]. Kraków: Wydawnictwo Uniwersytetu Jagiellońskiego.

Polczyk, R. (2017). The 'memory' misinformation effect may not be caused by memory failures : Exploring memory states of misinformed participants. Polish Psychological Bulletin, 48(3), 388-400.

Poole, D. A., \& Lindsay, D. S. (2002). Reducing child witnesses' false reports of misinformation from parents. Journal of Experimental Child Psychology, 81(2), 117-140.

Roebers, C. M. (2002). Confidence judgments in children's and adult's event recall and suggestibility. Developmental Psychology, 38(6), 1052-1067.

Roediger, H. L., \& McDermott, K. B. (1995). Creating false memories: Remembering words not presented in lists. Journal of Experimental Psychology: Learning, Memory, and Cognition, 21(4), 803-814.

Rogalski, Y., Altmann, L. J. P., \& Rosenbek, J. C. (2014). Retrieval practice and testing improve memory in older adults. Aphasiology, 28(4), 381-400.

Rosenthal, R., \& Rosnow, R. L. (1985). Contrasts analysis: Focused comparisons in the analysis of variance. Cambridge: Cambridge University Press.

Saywitz, K. J., \& Moan-Hardie, S. (1994). Reducing the potential for distortion of childhood memories. Consciousness and Cognition, 3(3-4), 408-425.

Schacter, D. L. (1999). The seven sins of memory: Insights from psychology and cognitive neuroscience. American Psychologist, 54(3), 182-203.

Schul, W., Liu, W., Xu, H. Y., Flamand, M., \& Vasudevan, S. G. (2007). A dengue fever viremia model in mice shows reduction in viral replication and suppression of the inflammatory response after treatment with antiviral drugs. The Journal of Infectious Diseases, 195(5), 665-674.

Szpitalak, M. (2015). W kierunku poprawy jakości zeznań świadków: pozytywne i negatywne nastepstwa ostrzegania o dezinformacji. [Towards improving human testimony: Negative consequences of 
warning against misinformation]. Kraków: Wydawnictwo Uniwersytetu Jagiellońskiego.

Szpitalak, M., \& Polczyk, R. (2010). Warning against warnings: Alerted participants may perform worse. Misinformation, involvement and warning as determinants of witness testimony. Polish Psychological Bulletin, 41(3), 105-112.

Szpitalak, M., \& Polczyk, R. (2011). Can warning harm memory? The impact of warning on eyewitness testimony. Problems of Forensic Sciences, 86, 140-150.

Szpitalak, M., \& Polczyk, R. (2013). Promoting eyewitness testimony quality: Warning vs. reinforced self-affirmation as methods of reduction of the misinformation effect. Polish Psychological Bulletin, 44(1), 85-91.

Swanger, M. M. (2015). Using a computerized program to improve working memory in intermediate school students. ProQuest Information \& Learning. (2015-99210-586).

Thomas, A. K., Bulevich, J. B., \& Chan, J. C. (2010). Testing promotes eyewitness accuracy with a warning: Implications for retrieval enhanced suggestibility. Journal of Memory and Language, 63(2), 149-157.

Tousignant, J. P., Hall, D., \& Loftus, E. F. (1986). Discrepancy detection and vulnerability to misleading postevent information. Memory \& Cognition, 14(4), 329-338.

Tulving, E. (1967). The effects of presentation and recall of material in free-recall learning. Journal of Verbal Learning and Verbal Behavior, 6(2), 175-184.

Vredeveldt, A., \& Penrod, S. D. (2013). Eye-closure improves memory for a witnessed event under naturalistic conditions. Psychology, Crime \& Law, 19(10), 893-905.
Wells, G. L., Memon, A., \& Penrod, S. D. (2006). Eyewitness evidence: Improving its probative value. Psychological Science in the Public Interest, 7(2), 45-75.

Wells, G. L., \& Olson, E. A. (2003). Eyewitness testimony. Annual Review of Psychology, 54(1), 277-295.

Wells, G. L., \& Turtle, J. W. (1987). Eyewitness testimony research: Current knowledge and emergent controversies. Canadian Journal of Behavioural Science, 19(4), 363-388.

Winkelspecht, S. M., \& Mowrer, R. R. (1999). Memory distortion: Can accurate memory be preserved? The Psychological Record, 49(1), $137-144$.

Wiśniacka, R. (1933). Psychologia zeznań świadków. [the psychology of human testimony]. Archiwum Kryminologii, 2, 215-219.

Wright, D. B. (1993). Misinformation and warnings in eyewitness testimony: A new testing procedure to differentiate explanations. Memory, 1(2), 153-166.

Zelinski, E. M., Spina, L. M., Yaffe, K., Ruff, R., Kennison, R. F., Mahncke, H. W., \& Smith, G. E. (2011). Improvement in memory with plasticity-based adaptive cognitive training: Results of the 3month follow-up. Journal of the American Geriatrics Society, 59(2), 258-265.

Zuniga, K. E., Mueller, M., Santana, A. R., \& Kelemen, W. L. (2018). Acute aerobic exercise improves memory across intensity and fitness levels. Memory, 1-9.

Publisher's Note Springer Nature remains neutral with regard to jurisdictional claims in published maps and institutional affiliations. 